\title{
Quem chama a atenção é o professor? O dinamismo dos posicionamentos em uma Sala de Aula de PFOL
}

Ricardo Moutinho ${ }^{1}$

Resumo: O posicionamento é um fenômeno sociointeracional dinâmico que é assumido pelos participantes por meio de tomadas de decisão durante um encontro social. Mesmo em situações hierárquicas rígidas, há sempre espaços para improvisos (ou ruídos) que provocam uma alteração na maneira esperada de se participar, renegociando os posicionamentos institucionalmente impostos. Desse modo, como já argumentado em Rae (2001), Kasper (2004) e Rampton (2006), partimos do princípio de que posicionamento não é uma categoria analítica estática, mas sim algo passível de renegociação e transformação no momento em que os sujeitos reorganizam o espaço interativo. Para este trabalho, discutiremos alguns dados coletados em uma sala de aula de Português para Falantes de Outras Línguas (PFOL) de nível primário em um contexto de ensino/aprendizagem luso-chinês. A professora, embora sendo a figura central da sala, não consegue manter esse "papel" durante toda a aula, perdendo momentaneamente o seu status de controladora da interação.

Palavras-chave: posicionamentos; reorganização do espaço interativo; PFOL.

\section{Papés e posicionamentos}

Em sala de aula, há uma configuração do espaço interativo préconcebida por professores e alunos baseada nos direitos e deveres que esses possuem. Nos termos mais tradicionais, enquanto o sujeito que está no papel de professor tem o direito de chamar a atenção de um aprendente ou de tomar (ou passar) a palavra quando bem entender, o sujeito que está no papel de aluno tem o dever de responder apenas quando chamado ou de obedecer às regras impostas a ele.

Porém, nem mesmo em um contexto de ensino altamente hierarquizado essa configuração será estável. Há momentos em que esses direitos e deveres, mesmo que temporariamente, são renegociados e alunos podem "assumir" o papel de professor ou vice-versa (MOUTINHO, 2012; BJÖRK-WILLÉN, 2008; ROSA, 2008; SCHULZ, 2007; RAMPTON, 2006; CANDELA, 2005; KASPER, 2004; CANDELA, 1999; HERAS, 1994;

\footnotetext{
${ }^{1}$ Professor do Departamento de Letras da Universidade de Macau. Co-investigador do Projeto de Pesquisa: Interactions in Classroom of Portuguese as a Foreign Language and the Building of the Textual Competence: The Macau's Context, coordenado pelo Prof. Dr. Roberval Teixeira e Silva, do Departamento de Português da Universidade de Macau. Email: moutinho@umac.mo
}

50 fragmentum, N. 35, parte II. Laboratório Corpus: UFSM, Out./ Dez. 2012 
CANDELA, 1991; ERICKSON, 1982). Por essa razão, o termo "papel" deve ser problematizado. Quando tratamos de um fenômeno dinâmico, que pode ser alterado ao longo de um encontro social, necessitamos de um conceito menos enraizado nos moldes tradicionais da sociologia que possa explicitar um significado menos assente e generalizador. Portanto, trabalho com o conceito de "posicionamento" (VAN LANGENHOVE e HARRÉ, 1999; HERAS, 1994) por marcar esse dinamismo que está mais em sintonia com o viés teórico adotado neste trabalho.

\section{Uma breve revisão bibliográfica}

$\mathrm{Na}$ literatura, o trabalho que iniciou a discussão sobre o dinamismo dos posicionamentos em sala de aula data da década de 1980. Erickson (1982) encontrou momentos de rupturas nas "ações orquestradas" durante atividades em sala. $\mathrm{O}$ autor reporta situações em que aprendentes renegociam os seus posicionamentos de alunos e tomam a palavra do colega para fazerem uma correção ou um comentário. Nesse momento, o aprendente passa momentaneamente para um posicionamento de professor, pois corrige o seu colega na frente dos demais (ação essa institucionalmente conferida ao ensinante), alterando a "estrutura de tarefa acadêmica" (academic task structure) da sala de aula. Esse trabalho pioneiro de Erickson é de fundamental importância para entendermos como aspectos presentes em um nível macrossocial (a aparente passividade dos alunos e o respeito à figura central do professor em sala de aula) podem ser ressignificados por meio de ações mais "situadas" e pertencentes a um encontro social específico. Embora o espaço interativo da sala de aula não seja impermeável às influências do mundo social que a rodeia, há uma certa "produção local" que faz da sala de aula um microcosmo até certo ponto particular, com suas próprias características e desdobramentos.

Candela (1991; 1999; 2005) e Heras (1994) também trazem exemplos dessa natureza em aulas de ciências e de história em escolas primárias localizadas na Cidade do México. Com base em Heras (Ibid.), por exemplo, embora escolas sejam geralmente vistas como espaços que têm uma estrutura organizacional rígida, os posicionamentos de professores e alunos são interacionalmente reconstituídos, o que abre a possibilidade de "amolecimento" dessa estrutura e consequente renegociação do status de cada participante. O ponto mais crucial para a nossa discussão, retirado dos dados das autoras citadas acima, é o fato de os aprendentes tomarem a palavra do professor para corrigi-lo durante uma atividade, invertendo os posicionamentos de "professor" e "aluno" por diversas vezes durante a aula (fato esse que até então não tinha sido relatado na literatura até a publicação do trabalho de Candela, 1991). Outros autores reportaram resultados parecidos 
(MOUTINHO 2012; BJÖRK-WILLÉN, 2008; ROSA, 2008; SCHULZ, 2007; RAMPTON, 2006; KASPER, 2004).

A participação mais ativa por parte do aluno e a consequente apropriação ou "usurpação" (BAKHTIN, 1986) do posicionamento institucionalmente conferido ao professor é um fenômeno positivo para a interação em sala de aula caso seja trabalhado de maneira a satisfazer a possibilidade da co-construção do conhecimento. Desse modo, o aluno deixa de ser o recipiente de informações e passa a ser também um elaborador de pressupostos, contribuindo para o seu próprio aprendizado. Rampton (2006), em seu estudo sobre o discurso em sala de aula de uma escola localizada em uma área central de Londres, defende que esse fenômeno da apropriação do posicionamento do professor por parte do aluno é fortemente influenciado pelo aparecimento, a partir do final da década de 1970, de outro fenômeno chamado de "conversacionalização do discurso público" (FAIRCLOUGH, 1992). O dialogismo presente na mídia, especialmente nos programas televisivos de talkshow invadem o discurso político, profissional e o pedagógico. Por isso, o espaço interativo em sala de aula começa a se adaptar a essa nova realidade, o aluno "ganha" voz e o professor não consegue manter o controle da interação durante todo o tempo em sala. Para Rampton, há uma tendência, na sociedade atual, de se (re)negociar regras, identidades ou qualquer outro aspecto sociocultural que antes parecia ser estático. Segundo o autor, esse tipo de comportamento por parte dos aprendentes pode ser classificado como "exuberante", pois não se limita às regras impostas pelo ensino baseado em valores tradicionais, em que o professor é a figura central com o direito à palavra e o aluno, um mero sujeito passivo sem ações próprias.

Os dados de nosso trabalho também relatam ocorrências da mesma natureza em um contexto primário de ensino/aprendizagem de Português para Falantes de Outras Línguas (PFOL) em uma escola luso-chinesa ${ }^{2}$ de Macau. Tanto a professora quanto os aprendentes, quase todos de origem chinesa e um aluna filipina, renegociam ao tempo todo os seus posicionamentos durante as atividades em sala de aula. Focamos a nossa análise nos momentos de "chamadas de atenção", ação essa comumente realizada por professores. Porém, como poderemos observar nos dados, mesmo tratando-se de um contexto tradicional de ensino (com regras e posicionamentos bem definidos para cada participante), os aprendentes frequentemente se apropriavam do

\footnotetext{
2 As escolas luso-chinesas são instituições de ensino que oferecem o currículo regular de qualquer escola com o diferencial de ensinar PFOL em todos os anos. A língua veicular é o cantonês, com a exceção da seção portuguesa das escolas luso-chinesas, onde o português é língua veicular e ensinado como língua materna. Na sua maioria frequentadas por alunos chineses, atualmente, há uma rede de seis escolas primárias luso-chinesas em Macau, dois jardins-de-infância, duas escolas secundárias (uma regular e outra técnico-profissional) e o ensino recorrente primário e secundário para adultos.
} 
posicionamento da professora para efetuar algum reparo durante as atividades em sala. A seguir, fornecemos alguns exemplos retirados de três aulas. Essas aulas são parte de um corpus composto por 38 aulas gravadas em vídeo durante um semestre letivo. Os trechos analisados neste trabalho foram retirados das aulas de número 12, 22 e $35^{3}$.

\section{Exemplos de reparos realizados pelos aprendentes}

Observamos, no primeiro excerto, retirado de uma das aulas observadas, um reparo efetuado por um aprendente que corrige o seu colega e a professora, de codinome Roberta. As palavras em negrito e itálico são traduções de falas originalmente produzidas em cantonês, a língua materna da professora e dominada por todos os alunos.

Excerto 1: Aula 17 (p.6) 15-19

\begin{tabular}{|c|l|l|}
\hline 15 & Roberta & $\begin{array}{l}\text { Vamos ver aqui! ((mostra o livro aos alunos)) } \\
\text { Que palavras aprendemos hoje? }\end{array}$ \\
\hline 16 & Aluno & Quatro! \\
\hline 17 & Roberta & Cinco, seis, sete, oito! \\
\hline 18 & Aluno & Já aprendemos oito palavras! \\
\hline 19 & Aluno & Não! Só quatro palavras! \\
\hline
\end{tabular}

Após a resposta de um aluno (linha 16) e a correção por parte da professora (linha 17), um outro aprendente toma o turno (linha 18) para apoiar a retificação de Roberta. Nesse momento, o aluno em questão atua como "patrocinador" (LEVINSON, 1988) da professora, uma vez que defende publicamente a observação que a mesma fez na linha 17 . Na linha 19, temos uma outra reorganização do espaço interativo, porém, dessa vez, com um outro aluno discordando da correção de Roberta e, consequentemente, do ato de apoio de seu colega à fala da professora. A elocução produzida na linha 19 "usurpa", portanto, o posicionamento institucionalmente conferido à professora, que é o de corrigir alguma produção equivocada.

Quase sempre, essas reações de reprovação por parte dos aprendentes provocam uma alteração de posicionamentos, com os alunos corrigindo a professora. No trecho seguinte, temos mais um exemplo dessa natureza.

\footnotetext{
${ }^{3}$ É importante mencionar que foram observados vários movimentos de apropriação do discurso do professor por parte dos aprendentes durante um semestre letivo. Porém, por razão da limitação de espaço, apresentaremos apenas alguns exemplos. Para uma apresentação de dados mais ampla e uma discussão mais aprofundada, ver Moutinho (2012).
} 
Excerto 2: Aula 22 (p.17) 1-15

\begin{tabular}{|l|l|l|}
\hline 1. & Alunos & Wong Hou Lam?! \\
\hline 2. & Roberta & Bom, Hou Lam. \\
\hline 3. & Alunos & Onome é U Hou Lam. \\
\hline 4. & Roberta & Bom, Hou Lam. \\
\hline 5. & Alunos & O nome é U Hou Lam. \\
\hline 6. & Roberta & Tá bom! \\
\hline 7. & Aluna & Ela disse "Bom, Hou Lam." \\
\hline 8. & Alunos & $(? ? ?)$ \\
\hline 9. & Roberta & U Hou Lam! Deixa-me ver se ele sabe. Shh! \\
\hline 10. & Roberta & Olhos. \\
\hline 11. & Alunos & Olhos. \\
\hline 12. & Roberta & Onde estão? \\
\hline 13. & Roberta & Olhos, aponta. \\
\hline 14. & Aluno & Olhos. ((apontando para os seus olhos)) \\
\hline 15. & Roberta & Ohhh! \\
\hline
\end{tabular}

No exemplo acima, há uma tomada de turno por parte dos alunos (linha 3) para corrigir Roberta que tinha se equivocado ao proferir o nome de um aluno (linha 1). Com essa "chamada de atenção", os alunos apropriam-se do posicionamento da professora e reorganizam o espaço interativo. A professora aceita a correção (linha 6) e os alunos passam, então, a discutir qual teria sido o equívoco de Roberta (linhas 7 e 8). Logo após, Roberta toma o turno (linha 9), mas, dessa vez, proferindo corretamente o nome do aprendente (U Hou Lam) e, retomando o seu posicionamento de professora, direciona-se ao aluno em questão para lhe fazer uma pergunta.

Como é possível observar no caso apresentado anteriormente, a professora não tem qualquer reação negativa quanto à apropriação do discurso institucional por parte dos alunos, uma vez que aceita a correção dos mesmos. Porém, apesar desse movimento parecer ser considerado "normal", Roberta rapidamente retoma o seu posicionamento de professora na linha 9, pedindo silêncio e dirigindo-se novamente a U Hou Lam para dar continuidade à atividade (linhas 10-12).

No próximo exemplo, um aluno nota que havia alguns cartazes colados em diversos cantos da sala com os nomes de vários objetos que estavam no item de um teste que estava sendo aplicado naquele momento. Por essa razão, o aprendente chama a atenção de Roberta, apropriando-se do posicionamento de professor e, consequentemente, reorganizando o espaço interativo. 
Excerto 3: Aula 35 (p.4) 29-46

\begin{tabular}{|c|c|c|}
\hline $\begin{array}{l}29 \\
30\end{array}$ & Roberta & $\begin{array}{l}\text { Bom. Liga a primeira frase imediatamente. É o } \\
\text { lápis e a caneta. Já está? }\end{array}$ \\
\hline 31 & Alunos & Já está. \\
\hline 32 & Roberta & $\begin{array}{l}E \text { E a primeira frase.....vão ligar a primeira frase.. É } \\
\text { o lápis.. }\end{array}$ \\
\hline 33 & Aluno & Professora Roberta. \\
\hline 34 & Roberta & ...e a caneta. \\
\hline 35 & Aluno & $\begin{array}{l}\text { Professora, }((\text { Roberta olha para o aluno })) \text { tem } \\
\text { algumas respostas coladas na mesa e na porta. }\end{array}$ \\
\hline 36. & Roberta & $\begin{array}{l}\text { ((retirando os cartazes da mesa e da porta, porém } \\
\text { continuando a explicar as instruções do teste para a } \\
\text { sala) }) \text { E você vai ligar... }\end{array}$ \\
\hline 37. & Aluno & $\begin{array}{l}\text { Mais uma. ((referindo-se a mais um cartaz colado na } \\
\text { porta)) }\end{array}$ \\
\hline 38. & Roberta & $\begin{array}{l}((\text { retirando o cartaz })) \text { Tá bom? ((dirigindo-se ao } \\
\text { aluno)) }\end{array}$ \\
\hline 39 & Aluno & Mesa.... \\
\hline 40 & Alunos & Mais uma.... [mais uma.. \\
\hline 41 & Roberta & Tá bom? obrigada. ((retirando o cartaz da mesa)) \\
\hline 42 & Alunos & $\begin{array}{l}\text { Ali..ali. ((referindo-se a um cartaz colado no armário } \\
\text { da sala)) }\end{array}$ \\
\hline $\begin{array}{l}43 . \\
44 . \\
45\end{array}$ & $\begin{array}{l}\text { Roberta } \\
\text { Roberta } \\
\text { Roberta }\end{array}$ & $\begin{array}{l}\text { Ali não é preciso. O cartaz do armário não é preciso. } \\
\text { Não faz mal. Tá bom. } \\
\text { Vamos continuar. Não é preciso aquele. Tá bom. } \\
\text { Número um, já está? } \\
\text { Já está? }\end{array}$ \\
\hline 46 & Alunos & Sim. \\
\hline
\end{tabular}

Observamos que a primeira tentativa do aprendente em tomar o turno (linha 33) não foi bem sucedida, pois Roberta ainda continua a endereçar a sala, terminando de concluir a sua explicação iniciada na linha 32. Porém, o aluno insiste em tomar o turno (linha 35) e, finalmente, consegue a atenção da professora. Nesse momento, o aprendente, apropriando-se do posicionamento de professor, chama a atenção de Roberta, apontando para os cantos da sala onde havia cartazes fixados. É possível observar esse momento na Figura 1 a seguir. 


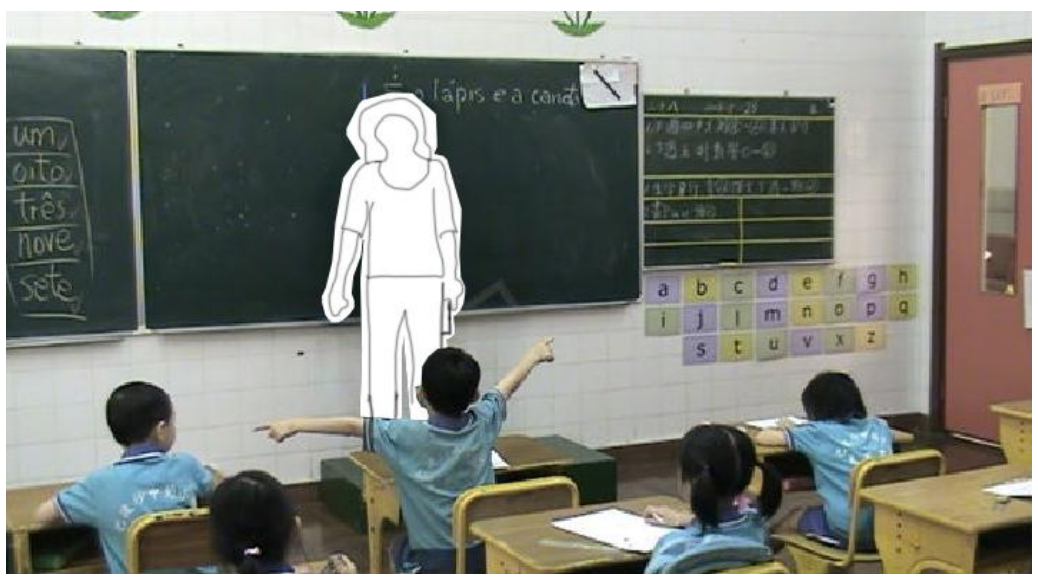

Figura 1: Um aluno chama a atenção de Roberta, apontando para os locais onde havia cartazes que continham respostas do teste.

Fonte: Arquivo pessoal.

Após retirar os cartazes aos quais o aprendente se referia, Roberta ainda é surpreendida pelo mesmo aluno (linhas 37 e 39), pedindo para que a professora retirasse mais dois cartazes fixados na porta e na mesa. Roberta, mesmo tentando recuperar o seu papel de professora e continuar a aula, realinhando, assim, os alunos novamente no enquadre teste $e$, consequentemente, recuperando o seu posicionamento de professora, vê-se obrigada a continuar ratificando o aluno como falante e atendendo às suas "ordens".

O aprendente, portanto, continua usurpando o posicionamento institucionalmente conferido à Roberta e, na linha 40, é apoiado pelos seus colegas, que se juntam a ele para chamar a atenção da professora para o fato de haver mais um papel colado na mesa (linha 39). Nesse momento, o restante dos alunos atua como patrocinador do aprendente que frequentemente se apropriava do posicionamento de professor.

No entanto, os alunos (linha 42), ao continuarem chamando a atenção de Roberta para um outro cartaz fixado no armário da sala, não obtém o mesmo sucesso de seu colega. Nesse instante, a professora, recuperando o seu posicionamento institucional (linhas 43-45), diz que não era preciso retirar o cartaz em questão, e, assim, realinha a sala no enquadre teste (linha 29), contando com a aceitação dos alunos e o consequente reposicionamento dos mesmos (linha 46).

56 fragmentum, N. 35, parte II. Laboratório Corpus: UFSM, Out./ Dez. 2012 


\section{Algumas conclusões}

Neste artigo, realizamos uma breve exposição de exemplos de apropriação do posicionamento de professor por parte dos alunos em uma sala de aula primária de PFOL de uma escola luso-chinesa de Macau. Iniciamos o trabalho discutindo sobre os termos "papel" e "posicionamento". Em seguida, passamos ao relato de alguns trabalhos na literatura que já abordaram o tema. Finalmente, apresentamos os nossos resultados, retirados de três aulas gravadas em vídeo.

Como foi possível observar, na sala de aula analisada, a apropriação do posicionamento de professor por parte dos aprendentes não acontece logo nos primeiros encontros (basta observar que o primeiro movimento dessa natureza registrado neste trabalho foi retirado da aula de número 17). Isso talvez se deva à confiança que os alunos adquirem durante um certo período de tempo. Depois de desenvolver um certo grau de emancipação, há uma possibilidade maior de testemunharmos situações desse tipo (alunos participando de maneira mais ativa). Contudo, não podemos tomar isso como regra, uma vez que, em cada contexto, esse processo desenvolve-se de forma distinta. O que podemos afirmar é que essa emancipação deve ser encorajada pelo professor para que movimentos de apropriação ocorram de maneira frequente, pois exercer a autoridade de maneira tradicional pode inibir os aprendentes a atuarem como sujeitos elaboradores de pressupostos. Esse fator é fundamental se quisermos que nossos alunos sejam agentes ativos na construção do conhecimento dentro de sala de aula, transformando o contexto escolar em um espaço interativo mais dinâmico e mais próximo daquele encontrado em situações reais do cotidiano.

\section{Referências}

BAKHTIN, M. M. Speech Genres and Other Late Essays. Trans. by Vern W. McGee. Austin, Texas: University of Texas Press, 1986.

BJÖRK-WILLÉN, P. Routine trouble: how preschool children participate in multilingual instruction. Applied Linguistics, v. 29, n. 4, 2008. p. 555-577.

CANDELA, A. Argumentación y conocimiento científico escolar. Infancia y Aprendizaje, 55, 1991, p. 13-28.

- Students' power in classroom discourse. Linguistics and Education, n.10 (2). 1999, p. 139-163.

Students' participation as co-authoring of school institutional practices. Culture \& Psychology, 11 (3), 2005, p. 321-337.

ERICKSON, F. Classroom discourse as improvisation: relationships between academic task structure and social participation structure in lessons. In: 
WILKINSON, L. C. Communicating in the Classroom. AP Academic Press, 1982.

FAIRCLOUGH, N. Discourse and Social Change. Cambridge: Polity Press, 1992.

HERAS, A. I. The construction of understanding in a sixth-grade bilingual classroom. Linguistics and Education, n.5, 1994, p. 275-299.

KASPER, G. Participant orientations in German conversation-for-learning. The modern language journal, 88, IV, 2004, p. 551-567.

LEVINSON, S. C. Putting linguistics on a proper footing: Exploration on Goffman's concept of participation. In: P. Drew \& Wooton (Eds), Exploring the interaction order. Boston: Northeastern University Press. 1988. p.161-227. MOUTINHO, R. A reconfiguração das estruturas de participação em uma sala de aula de PFOL de uma escola primária em Macau: renegociando regras e redefinindo papéis em um contexto de ensino/aprendizagem luso-chinês. Tese de Doutorado. Universidade de Macau, 2012.

RAE, J. Organizing participation in interaction: doing participation framework. Research on Language \& Social Interaction, 34: 2, 2001, p. 253278.

RAMPTON, B. Language in late modernity: Interaction in an urban school. Cambridge Univesrity Press, 2006.

ROSA, A. P. da. É o professor quem diz quando se fala? A tomada de turnos de fala em atividades diferentes em uma turma de $1^{a}$ série em educação bilingüe. Dissertação de Mestrado. Porto Alegre: UFRGS, 2008.

SCHULZ, L. A construção da participação na fala-em-interação de sala de aula: um estudo microetnográfico sobre a participação em uma escola municipal de Porto Alegre. Dissertação de Mestrado. Porto Alegre: UFRGS, 2007.

VAN LANGENHOVE, L.; HARRÉ, R. Positioning theory: moral contexts of intentional action. Oxford: Blackwell Publishers, 1999.

58 fragmentum, N. 35, parte II. Laboratório Corpus: UFSM, Out./ Dez. 2012 